\title{
EFFECT OF ADDITION OF DEXAMETHASONE TO LOCAL ANAESTHETICS IN SUPRACLAVICULAR BRACHIAL PLEXUS BLOCK
}

\author{
Islam $\mathrm{SM}^{1}$, Hossain $\mathrm{MHMD}^{2}$, Maruf $\mathrm{AA}^{3}$
}

\begin{abstract}
Introduction: Many-a-time local anaesthesia appears as a very effective alternative of general one. Different additives have been used to prolong regional blockade.

Objective: This prospective study designed to evaluate the effect of dexamethasone added to local anaesthetics on the onset and duration of supraclavicular brachial plexus block.

Methods: Sixty adult patients undergoing various orthopaedic surgeries on forearm and around the elbow under supraclavicular brachial plexus block were selected and divided into 2 groups of 30 each. In group-A patients received $35 \mathrm{ml}$ of mixture of lignocaine $2 \%$, bupivacaine $0.5 \%$ while in group-B patients received the same amount of local anaesthetics with dexamethasone $(8 \mathrm{mg})$. The onset of sensory and motor block and duration of analgesia in two groups were compared and development of complications were observed.
\end{abstract}

Result: The two groups were comparable in demographic data. The mean onset time of sensory block was $11.64 \pm 2.19$ minutes in group $A$ and $9.89 \pm 1.97$ minutes in group $B$ and difference was statistically significant $(\mathbf{p}<\mathbf{0 . 0 5})$. Onset of motor block was $13.32 \pm 0.98$ minutes in group $A$ and $11.09 \pm 1.28$ minutes in group B and difference was statistically significant $(\mathbf{p}<0.05)$. There was markedly prolonged duration of analgesia in group-B, $11.87 \pm 0.53$ hours compared to group-A, $3.43 \pm 0.49$ hours. The result was statistically highly significant $(p<0.001)$. Both the groups had high success rate $(>90 \%)$. The incidence of complication was low in both the groups.

Conclusion: Addition of dexamethasone as an adjuvant to local anaesthetics in brachial plexus block results in significantly early onset and markedly prolonged duration of analgesia without any unwanted effects.

Key words: Supraclavicular block, analgesia, local anaesthetics, dexamethasone

\section{Introduction}

Brachial plexus block is a versatile and reliable regional anaesthetic technique with multiple applications. Now-a- days, it is a suitable alternative to general anesthesia in certain patients. It is a block of roots, divisions and cords, first performed by Halsted in $1884^{1}$. The supraclavicular block of the brachial plexus has many advantages over other approaches to brachial plexus block $^{2,3,4}$. It has the reputation of providing most complete and reliable anesthesia for upper limb surgery. It is performed at the trunk level where the plexus is presented most compactly. This anatomic compactness is responsible for complete and reliable anesthesia. Another advantage is that it can be performed with the patient's arm in any position to provide excellent anesthesia for elbow, forearm and hand surgery ${ }^{5}$.

Local anaesthetics alone provide analgesia for not more than 4-8 hours. Increasing the duration of local anesthetic action is often desirable because it prolongs surgical anesthesia and analgesia. Different additives have been used to prolong regional blockade. Vasoconstrictors can be used to vasoconstrict vessels, thereby reducing vascular absorption of the local anesthetic. Additives like opioids, clonidine, verapamil etc were added to local anaesthetics, but the results are either inconclusive or associated with side effects ${ }^{6-8}$. Steroids when used intrathecally are reported to cause arachnoiditis but there is no evidence suggesting any neuritis when steroids are used in low concentration in peripheral nerve blocks. Steroids have powerful antiinflammatory as well as analgesic property. Perineural injection of steroids is reported to influence post operative analgesia. They relieve pain by reducing inflammation and blocking transmission of nociceptive C-fibres and by suppressing ectopic neural discharge ${ }^{9}$. Some studies have demonstrated the analgesic effect of local spinal and systemic corticosteroids in combination with bupivacaine $\mathrm{e}^{10,11}$. Dexamethasone microspheres have been found to prolong the block duration in animal and human studies and adding methyl prednisolone to local anesthetic increases the duration of axillary brachial block $^{12-15}$.

With this background, this study was carried out to evaluate the efficacy of dexamethasone as an adjuvant to mixture of local anaesthetics in supraclavicular brachial

1. Col Md Saiful Islam MBBS, MCPS, FCPS, Professor of Anaesthesiology, AFMC; 2. Brig Gen MHM Delwar Hossain MBBS, DA, MCPS, FCPS, Professor of Anaesthesiology, AFMC, Dhaka; 3. Lt Col Abdullah Al Maruf MBBS, FCPS, Classified Specialist in Anaesthesiology, CMH, Dhaka. 
plexus block. Onset of sensory and motor blockade and duration of analgesia were observed.

\section{Materials and Methods}

This prospective study was performed at Combined Military Hospital (CMH), Dhaka in one calendar year from January 2009 to December 2009. After departmental approval and obtaining written informed consent from the patients, 60 American Society of Anaesthesiologist (ASA) physical status I or II patients of either sex, aged 18-60 years scheduled for elective or emergency orthopaedic surgeries of upper limb under supraclavicular brachial plexus block were included in this study. Patients with history of uncontrolled diabetes, renal and liver diseases, circulatory instability, pregnant women, and peptic ulcer disease, those with allergy to local anaesthetics and on long term steroid therapy were excluded from the study.

Patients were distributed into 2 groups of 30 each. In Group-A patients received $15 \mathrm{ml}$ of lignocaine $2 \%, 15$ $\mathrm{ml}$ of bupivacaine $0.5 \%$ while in Group-B patients received injection dexamethasone $2 \mathrm{ml}(8 \mathrm{mg})$ in addition to the above mixture. Total volume was made to $35 \mathrm{ml}$ by adding distilled water in both the groups. On arrival to the operating room, multi-para monitor was attached and the initial pulse, blood pressure (BP), respiratory rate, $\mathrm{SpO} 2$ was recorded as pre-block values. A 20 gauge IV cannula was inserted in a peripheral vein in the contra lateral arm. After appropriate patient positioning and strict aseptic and antiseptic precautions midclavicular point, external jugular vein and subclavian artery pulsation were identified. About $2 \mathrm{~cm}$ above the midclavicular point just lateral to subclavian artery pulsation, a 24 gauge 1.5 inch needle was introduced and directed caudal and medially until paraesthesia was encountered, when $35 \mathrm{ml}$ of local anaesthetics with or without dexamethasone was injected in this area. After the procedure patients were taken for surgery. Time of onset of sensory block and onset of motor block were noted. Patients were monitored routinely and any untoward side effects were also noted. Duration of analgesia was measured by interviewing the patient in the postoperative ward. Analgesia was given when patients complained of pain. All results were expressed in mean+standard deviation (SD) or percentage as applicable. Statistical analyses were carried out using Statistical Package for Social Science (SPSS) for Windows Version 13.0. Results were considered statistically significant where $\mathrm{p}$ value was less than 0.05 .

\section{Results}

Patient's demographics were similar and fairly comparable in both groups and differences were statistically not significant (table-I). Operating conditions were pronounced satisfactory by the surgeon concerned in all the cases. Duration of surgical procedure was shown in Table-II. Duration was similar in both groups and differences were statistically not significant.

Table- I: Characteristics of patient

\begin{tabular}{|l|l|l|l|}
\hline Characteristics & $\begin{array}{l}\text { Group A } \\
(\mathbf{n = 3 0 )}\end{array}$ & $\begin{array}{l}\text { Group B } \\
(\mathbf{n = 3 0 )}\end{array}$ & p value \\
\hline Age (years) & $033.80 \pm 6.12$ & $030.31 \pm 4.73$ & $\mathrm{p}>0.05$ \\
\hline Body weight (Kg) & $059.10 \pm 7.21$ & $059.71 \pm 8.74$ & $\mathrm{p}>0.05$ \\
\hline Height (cm) & $155.25 \pm 3.49$ & $153.65 \pm 4.04$ & $\mathrm{p}>0.05$ \\
\hline $\begin{array}{l}\text { Sex } \\
\text { Male (number) }\end{array}$ & $20(66.66 \%)$ & $19(63.34 \%)$ & $\mathrm{p}>0.05$ \\
Female(number) & $10(33.34 \%)$ & $11(36.66 \%)$ & $\mathrm{p}>0.05$ \\
\hline $\begin{array}{l}\text { ASA physical status } \\
\text { I (number) }\end{array}$ & $17(56.66 \%)$ & $18(60.00 \%)$ & $\mathrm{p}>0.05$ \\
II (number) & $13(43.44 \%)$ & $12(40.00 \%)$ & $\mathrm{p}>0.05$ \\
\hline
\end{tabular}

Table -II: Duration of surgery in two groups

\begin{tabular}{|l|l|l|}
\hline Groups & $\begin{array}{l}\text { Duration of surgery } \\
\text { (in minutes) }\end{array}$ & p value \\
\hline Group A ( $\mathrm{n}=30)$ & $80.75 \pm 10.49$ & \multirow{2}{*}{$\mathrm{p}>0.05$} \\
\hline Group B $(\mathrm{n}=30)$ & $81.88 \pm 11.12$ & \\
\hline
\end{tabular}

Table -III: Comparison of quality of block in two groups

\begin{tabular}{|l|l|l|l|}
\hline Quality of block & $\begin{array}{l}\text { Group A } \\
(\mathbf{n = 3 0 )}\end{array}$ & $\begin{array}{l}\text { Group B } \\
(\mathbf{n}=\mathbf{3 0})\end{array}$ & $\mathbf{p}$ value \\
\hline $\begin{array}{l}\text { Onset of sensory } \\
\text { block (min) }\end{array}$ & $11.64 \pm 2.19$ & $09.89 \pm 1.97$ & $\mathrm{p}<0.05$ \\
\hline $\begin{array}{l}\text { Onset of motor } \\
\text { block (min) }\end{array}$ & $13.32 \pm 0.98$ & $11.09 \pm 1.28$ & $\mathrm{p}<0.05$ \\
\hline $\begin{array}{l}\text { Total duration of } \\
\text { analgesia (hour) }\end{array}$ & $03.43 \pm 0.49$ & $11.87 \pm 0.53$ & $\mathrm{p}<0.001$ \\
\hline
\end{tabular}

Table -IV: Incidence of side effects during block in two groups

\begin{tabular}{|l|l|l|l|}
\hline Side effects & $\begin{array}{l}\text { Group A } \\
(\mathbf{n = 3 0})\end{array}$ & $\begin{array}{l}\text { Group B } \\
(\mathbf{n}=30)\end{array}$ & p value \\
\hline Horner's syndrome & $12(40 \%)$ & $10(33.33 \%)$ & $\mathrm{p}>0.05$ \\
\hline $\begin{array}{l}\text { Dyspnoea or chest } \\
\text { discomfort }\end{array}$ & $02(6.66 \%)$ & $01(03.33 \%)$ & $\mathrm{p}>0.05$ \\
\hline $\begin{array}{l}\text { Recurrent laryngeal } \\
\text { nerve block }\end{array}$ & $01(3.33 \%)$ & $02(06.66 \%)$ & $\mathrm{p}>0.05$ \\
\hline Inadequate block & $01(3.33 \%)$ & $01(03.33 \%)$ & $\mathrm{p}>0.05$ \\
\hline
\end{tabular}

The qualities of block in two groups were shown in Table III. Onset of sensory as well as motor blocks were early in group B and was statistically significant $(\mathrm{p}<0.05)$ too. Duration of analgesia was markedly prolonged in group$B$ and was statistically highly significant $(\mathrm{p}<0.001)$. Horner's syndrome was observed as the main trouble in both the groups (Table-IV). Similar complications were observed in two groups and there were no statistically significant differences in complications. Inadequate block was observed in one patient in either groups and were managed with incremental intravenous analgesics. No serious complications like pleural puncture, pneumothorax or any other cardiorespriatory side effects were observed during the procedure. 


\section{Discussion}

Brachial plexus block is an easy and relatively safe procedure for upper limb surgeries. A combination of lignocaine and bupivacaine provided better operating conditions but the duration of analgesia is rarely maintained for more than 4-6 hours. Addition of steroid to local anaesthetics effectively and significantly prolongs the duration of analgesia as well as producing earlier onset of action ${ }^{16}$. Steroids are very potent antiinflammatory and immunosuppressive agents. Perineural injection of steroid is reported to influence postoperative analgesia. Epidural steroids were used for treatment of back pain and sciatica ${ }^{9}$. Various steroids has been used for this purpose, but dexamethasone a 9aderivative synthetic glucocorticoid is preferred because of its highly potent anti-inflammatory property, about 25-30 times as potent as hydrocortisone and without any mineralocorticoid activity. Thus was found to be safer and devoid of potential side effects.

Pre-operative administration of dexamethasone by oral and intravenous routes has been shown to reduce overall pain scores and analgesic requirements in the postoperative period without any adverse effects in various oral and general surgical procedures ${ }^{17}$. Dexamethasone is also known to reduce post-operative nausea and vomiting. The possible mechanism of analgesic and antiemetic actions are due to antiinflammatory property of Dexamethasone ${ }^{18,19}$.

In reported study significantly early onset of sensory and motor block was noticed in group-B compared to groupA $(p<0.05)$. The early onset of action might be due to synergistic action of dexamethasone with local anaesthetics on blockage of nerve fibres. The duration of pain relief (postoperative analgesia) was markedly prolonged in group-B (11.87 \pm 0.53 hours), while it was only $3.43 \pm 0.49$ hours in group-A $(\mathrm{p}<0.001)$. This results similar to findings of study of Shrestha BR et $\mathrm{al}^{20}$. Author reported onset of action of 10-30 min (mean $18.15 \pm 4.25 \mathrm{~min})$ in local anaesthetic group and 10-20 min (mean $14.15 \pm 2.10 \mathrm{~min}$ ) in local anaesthetic+steroid group, while duration of analgesia was 2.30-4 hours (mean 3.16 \pm 0.48 ) in local anaesthetic group and 8-24 hours (mean 12.75 \pm 5.33 ) in local anaesthetic+steroid group.

Preliminary works demonstrated that addition of corticosteroid microspheres to local anaesthetics prolonged the duration of blockade of peripheral nerves $^{14}$. It has been reported that intercostal injection of dexamethasone containing bupivacaine microcapsules produces prolonged duration of anaesthesia and analgesia in healthy human volunteers ${ }^{14}$. These authors believed that there was a causative relationship between the suppression of inflammation and the remarkably longer duration action. Few preliminary studies reported that steroids significantly prolong the duration of analgesia in extremity nerve blocks ${ }^{21}$. A study in axillary block, suggested that dexamethasone when added to lignocaine significantly prolonged duration of analgesia without any change in onset time ${ }^{21}$. Another study in supraclavicular block reported that dexamethasone when added as adjuvant to mixture of local anaesthetics resulted in significantly early onset and longer duration of analgesia ${ }^{22}$. Both the groups had high success rate $(>90 \%)$. The incidence of complication was low and comparable between the groups except higher incidence of Horner's syndrome. No case of clinical pneumothorax was observed in the present study. Horner's syndrome was observed in $40 \%$ patients in group A and $33.33 \%$ patients in group B which is comparable to the study of Niazi et $\mathrm{al}^{23}$. Dyspnoea or chest discomfort was encountered in $6.66 \%$ in group A and in $3.33 \%$ patient in group B respectively. Recurrent laryngeal nerve block was encountered in 3.33\% patient in group A and 6.66\% patient in group B, respectively; inadequate block was observed in one patient in either groups. Brand and Papper injected local anaesthetic agent by Murphy's supraclavicular route but had $6.1 \%$ incidence of pneumothora $\mathrm{x}^{24}$. In another study by this route Pham Dang et al observed asymptomatic Phrenic nerve paralysis (60\%), Horner's Syndrome (10\%) and transient recurrent nerve paralysis ${ }^{25}$. Dupre et al and Hampel et al also reported Horner's syndrome in their studies ${ }^{26,27}$. Kumar et al and Ross reported epidural and subdural blockade due to widespread distribution of anaesthetic agent with interscalenous route ${ }^{28,29}$. Dupre et al and Moore et al had $11 \%$ and $8 \%$ failure rates ${ }^{26,30}$. Brand and Papper had $84.4 \%$ success rate ${ }^{24}$.

Although corticosteroids have been used successfully for postoperative pain relief in oral, general and orthopedic surgery $^{31,32}$; other studies have not corroborated these reports $^{33,34}$. The mechanism of the analgesia induced by corticosteroids is not fully understood. This effect is suspected to be mediated by their anti-inflammatory or immune-suppressive effects ${ }^{35,36}$. The use of corticosteroids as an adjuvant to local anesthetic for peripheral nerve blocks rarely has been described and its mechanism of action is not clearly understood. According to the traditional theory of steroid action, steroids bind to intracellular receptors and modulate nuclear transcription. In this study, dexamethasone produced a relatively rapid effect which cannot be explained by the above mechanism ${ }^{37}$. Corticosteroids may have a local effect on the nerve; the dexamethasone effect may be related to this action ${ }^{38}$. Adverse effects with a single dose of dexamethasone are probably extremely rare and minor in nature and previous studies have demonstrated that short-term (24 hours) use of dexamethasone as safe $^{39}$. Adding a steroid to local anesthetic solution may not be indicated in all patients. For example, diabetic patients may experience 
hyperglycemia and patients with a continuing infectious process may be detrimentally affected by the antiinflammatory effects of steroids.

\section{Conclusion}

The use of dexamethasone to increase the duration of action of local anesthetics is not an indication of this drug. It may be useful in situations in which epinephrine must be used with caution (e.g., hypertension, ischemic heart disease).

\section{References}

1. Crile H. Great moments in the history of anaesthesiology in-A practice of anaesthesia 7th ed. London, UK: Lioyd-Luke; 2003. p.8.

2. Jeon DG, Kim W. Case series: ultrasound-guided supraclavicular block in 105 patients. Korean J Anesthesiol 2010 Mar; 58(3): 267-271.

3. Singh A, Gupta R, Vashisth M, Singh S, Kumari A, Aujla KS. Comparison of Effectiveness of Brachial Plexus Block by Supraclavicular and Axillary Approach Alone or in Combination. J Anaesth Clin Pharmacol 2010; 26(1): 31-34.

4. Yang CM, Kwon HU, Cho CK, et al. A comparison of infraclavicular and supraclavicular approaches to the brachial plexus using neurostimulation . Korean J Anesthesiol 2010 Mar; 58(3): 260-266.

5. Neal JM, Gerancher JC, Hebl JR, Ilfeld BM, et al. Upper Extremity Regional Anesthesia: Reg Anesth Pain Med 2009; 34(2): 134-170.

6. Wakhlo R, Gupta V, Raina A, Gupta SD, Lahori VU. Supraclavicular Plexus Block: Effect of Adding Tramadol or Butorphanol as an Adjuncts to Local Anaesthetic on Motor and Sensory Block and Duration of Post-operative Analgesia. J Anaesth Clin Pharmacol 2009; 25(1): 17-20.

7. Gabriella I, Adnane M, Desire-Pascal D, et.al. The effects of clonidine added to mepivacaine for paronychia surgery under axillary brachial plexus block. Anesth Analg 2005; 100(4):1179-1183.

8. Lalla RL, Anant S, Nanda HS. Verapamil as an Adjunct to Local Anaesthetic for Brachial Plexus Blocks. MJAFI 2010; 66: 22-24.

9. Benzon HT. Epidural steroids. In: Raj PP, editor. Pain medicine, a comprehensive review. UK: Mosby Publications; 1999. p.259-263.

10. Glasser RS, Knego RS,Delashaw JB, Fessler RG. The perioperative use of corticosteroids and bupivacaine in the management of lumbar disc disease. J Neurosurg 1993; 78: 383-7.

11. Mirzai H, Tekin I, Alincak H. Perioperative use of corticosteroid and bupivacaine combination in lumbar disc surgery: a randomized controlled trial. Spine 2002; 27: 343-6.

12. Castillo J, Curley J, Hotz J, et al. Glucocorticoids prolong rat sciatic nerve blockade in vivo from bupivacaine microspheres. Anesthesiology 1996; 85:1157-66.

13. Droger C, Benziger D, Gao F, Berde CB. Prolonged intercostals nerve blockade in sheep using controlled-release of bupivacaine and dexamethasone from polymer microspheres. Anesthesiology 1998; 89: 969-74.

14. Kopacz DJ, Lacouture PG, Wu D, et al. The dose response and effects of dexamethasone on bupivacaine microcapsules for intercostals blockade (T9 to T11) in healthy volunteers. Anesth Analg 2003; 96: 576-82.

15. Stan T, Goodman E, Cardida B, Curtis RH. Adding methylprednisolone to local anesthetic increases the duration of axillary block. Reg Anesth Pain Med 2004; 29: 380-382.

16. Golwala MP, Swadia VN, Dhimar AA, Sridhar NV. Pain Relief by Dexamethasone as an Adjuvant to Local Anaesthetics in Supraclavicular Brachial Plexus Block. J Anaesth Clin Pharmacol 2009; 25(3): 285-288. 17. Elhakim M, Ali NM, Rashed I, et al. Dexamethasone reduces postoperative vomiting and pain after paediatric tonsillectomy. Can.J Anaesth 2003; 50; 392-97.
18. Bisgaard T, Klarskov B. Pre-operative dexamethasone improves surgical outcome after laproscopic cholecystectomy. A randomized double blind placebo controlled trial. Ann Surg 2003; 238; 651-60.

19. Liu K, Hsu CC, Chia YY. Effect of dexamethasone on postoperative pain and emesis. Br J Anaesth 1998; 80; 85-86.

20. Shrestha BR, Maharjan SK, Tabedar S: Supraclavicular brachial plexues block with and without dexamethasone- A comparative study. KUMJ 2003; 1 (3): 158-160.

21. Movafegh A, Razazian M, Fatemeh H. Dexamethasone added to lidocaine prolongs Axillary brachial plexus blockade Anesth Analg 2006; 102; 263- 267.

22. Shrestha BR, Maharjan SK, Gautam B, Joshi MR. Comparative study between tramadol and dexamethasone as an admixture to bupivacaine in supraclavicular brachial plexus block. J Nepal Med Assoc 2007; 46(168): 158-64.

23. Masoud NG, Taghi MMM, Reza MG, Maarouf A, Seyedabolhasan S, Naser G. Complications of Supraclavicular Block of Brachial plexus using Compound Classic and Perivascular Techniques. Rawal Med J 2007; 32: 58-60.

24. Leonard B, Papper EM. A comparison of supraclavicular and axillary techniques for brachial plexus block. Anesthesiology 1961; 22: 226.

25. Dang CP, Gunst JP, Gouin F, et al. A novel supraclavicular approach to brachial plexus block. Anesth Analg 1997; 85: 111.

26. Dupre LJ, Danel V, Legrand JJ, Stiegtitz P. Surface Landmarks for supraclavicular block of the brachial plexus. Anesth Analg 1982; 61: 28.

27. Hampel V, Fink MV, Baumgartner E. A longitudinal supraclavicular approach to the brachial plexus for the insertion of plastic cannnulas. Anesth Analg 1981; 60: 352

28. Kumar A, Battit GE, Froese AB, Long MC. Bilateral Cervical and thorasic epidural blockade complicating interscalene brachial plexus block report of two cases. Anesthesiology 1997; 35: 651.

29. Ross S, Scarborought CP. Total spinal anaesthesia following brachial plexus block. Anesthesiology 1973; 39: 458.

30. Moore DC. Regional block. A hard book for use in the Clinical Practice of Medicine and Surgery. 4th ed. UK: Spring Field 1975. p.221.

31. Aasboe V, Raeder JC, Groegaard B. Betamethasone reduces postoperative pain and nausea after ambulatory surgery. Anesth Analg 1998; 87: 913-7.

32. Baxendale BR, Vater M, Lavery KM. Dexamethasone reduces pain and swelling following extraction of third molar teeth. Anaesthesia 1993;48:961-4.

33. Liu K, Hsu CC, Chia YY. Effect of dexamethasone on postoperative pain and emesis. Br J Anaesth 1998;80:85-6.

34. Tan P, Liu K, Peng CH, et al. The effect of dexamethasone on postoperative pain and emesis after intrathecal neostigmine. Anesth Analg 2001; 92: 228-32.

35. McCormack K. The spinal actions of nonsteroidal antiinflammatory drugs and the dissociation between their antiinflammatory and analgesic effects. Drugs 1994; 47: 28-45.

36. Ahlgren SC, Wang JF, Levine JD. C-fiber mechanical stimulusresponse functions are different in inflammatory versus neuropathic hyperalgesia in the rat. Neuroscience 1997; 76: 285-90.

37. Taguchi H, Shingu K, Okuda H, Matsumoto H. Analgesia for pelvic and perineal cancer pain by intrathecal steroid injection. Acta Anaesthesiol Scand 2002; 46: 190-3.

38. Devor MD, Gorvin-Lippmann R, Raber P. Corticosteroids suppress ectopic neural discharge originating in experimental neuromas. Pain 1985; 22: 127-37.

39. Splinter WM, Rhine EJ. Low-dose ondansetrone with dexamethasone more effectively decreases vomiting after strabismus surgery in children than does high-dose ondansetron. Anesthesiology 1998; 88: 72-5. 